REFLECTIONS:

NEUROLOGY AND THE

HUMANITIES

Section Editor

Michael H. Brooke, MD

\title{
Reflections for November
}

PMH:

Unclear-patient has no regular PMD but until recently was followed by ophthalmologist Dr. Gloucester-will obtain office records if possible-Gloucester currently on medical leave for bilateral enucleation.

\section{Current medications: none, NKDA}

\section{Family history: noncontributory}

\section{Psychosocial history:}

The patient, an ex-monarch, currently lives with his two married adult daughters, Goneril and Regan, traveling between their respective castles. He is estranged from his third daughter Cordelia, who is married and lives in France. He denies any current use of Etoh, illicits. Previously, patient had 24 hours home supervision, but his home health aide Mr. Fool has recently disappeared without any explanation.

\section{ROS:}

Skin: Patient notes of recent appearance "a boil, a plague-sore, an embossed carbuncle, in my corrupted blood." Unclear if this is an actual lesion or another reference to his troubled relationship with his children. He is followed by an outside dermatologist.

ROS otherwise noncontributory, see HPI.

\section{Exam:}

VS: T 97.8 HR 98 RR18 BP 125/83.

GEN-thin, unkempt elderly man dressed in wet clothing with a wreath of flowers in his hair.

RRR, CTAB, NTND, WWP no C/C/E.

\section{Neurological exam:}

MSE: Oriented to self only. Thinks he is in preArthurian Britain.

Speech fluent and prosodic - mostly iambic pentameter, some inappropriate content; patient perseverates on his ungrateful children, the loss of his kingdom and makes some inappropriately sexualized remarks objectifying women.

Calculation appears to be intact-patient enraged that his daughters want him to subtract "fifty followers" from his entourage of a "hundred knights" but he acknowledges that at least this number is "double five and twenty."

Naming, repetition, reading and comprehension grossly intact. 
Spontaneously writes sentence "I am a man more sinned against than sinning."

Some impairment of short term memory: patient cannot recall his motivation for having "divided in three our kingdom." Registers 3/3 "thankless" daughters, recalls 0/3@five minutes-Construction, extinction, neglect testing deferred. Endorses poor mood- "wilt break my heart?"

Cranial nerves:

I-Intact. Patient correctly indentified cloves by smell, then became agitated and began to complain how he "clovest" his "crown ... and gavest away both parts."

II-Visual fields full to confrontation, although patient complains "Mine eyes are not o' the best: I'll tell you straight."

III-XII grossly intact.

Muscle bulk-Normal bulk, and tone.

Rapid alternating movements, fine movements difficult to assess-patient uncooperative with exam. Reflexes-2+ bilateral biceps/triceps/BR 3+ patellars $1+$ AJs. Toes silent.

\section{Sensory:}

Pt has intact light touch, vibration, proprioception temperature bilaterally through legs and hands/ forearms, patient endorses subjective reduced pinprick bilaterally on the LE to T11/12 but notes "how sharper than a serpent's tooth it is to have a thankless child."

Coordination-patient uncooperative.

Gait-narrow-based.

Labs:

ABC, LFTs, BMP, B12, VRDL, thyroid panel pending.

\section{Studies:}

CT, MR brain-pending.

EEG-pending.

Differential:

Dementia-Patient's overall decline in executive functioning, memory loss, trouble with ADLs (e.g., getting dressed) suggest dementia, possibly Alzheimer disease, but more likely a vascular dementia, especially given the relatively precipitous decline in function as described by the patient's daughters. The patient may have suffered a stroke shortly before dividing up his kingdom and has since undergone a stepwise deterioration in function to the point that he requires constant supervision. His risk factors for a multi-infarct picture are not known, but given his lack of preventative medical care, he may well have a longstanding history of untreated hypertension. Infarcts will be visible on imaging, as will any significant cortical atrophy. The patient's personality changes and progressive fluent aphasia ("i' the clout: hewgh") may also be indicative of a frontotemporal dementia such as Pick disease.

Temporal lobe epilepsy_-The patient's olfactory hallucinations ("scalding, stench") and altered mental status may be indicative of mesial temporal lobe epilepsy. The patient's prior seizure history is not known-his symptoms could be the result of complex partial seizures resulting from mesial temporal sclerosis, a temporal lobe mass, trauma or infarct. EEG would demonstrate temporal sharp waves, and possible temporal intermittent rhythmic delta activity (TIRDA).

Brain tumor-A frontal lobe mass lesion could account for the patient's deficits in executive function, his personality changes, and his altered mental status. However, he has no history of headaches or visual field cuts. MR imaging will help confirm or rule out a mass lesion.

Chronic subdural hematoma-The patient does not have any known recent trauma, but he is not a reliable historian and there is some concern with elder abuse. His cognitive impairment could be the result of an occult subdural bleed, most likely on the left, given his language impairment. CT would be expected to show a concave hyperdensity compressing the brain that did not cross the midline. Given his significant neurologic defects, surgical drainage might be required.

A:

Elderly male of uncertain age who presents with altered mental status in the setting of progressive decline in cognitive function, most likely dementia vs temporal lobe epilepsy vs intracranial mass.

\section{Plan:}

f/u MR, EEG, psych consult, f/u labs_r/o metabolic disturbance.

If dementia-consider Aricept, discuss placement at SNF.

If temporal lobe epilepsy-address primary etiology if possible-consider carbamazepine.

If tumor or chronic subdural-neurosurg consult. 


\section{Neurology}

Reflections for November

Isadora Botwinick

Neurology 2009;73;1602-1603

DOI 10.1212/WNL.0b013e3181c0d443

\section{This information is current as of November 9, 2009}

\section{Updated Information \&}

Services

Permissions \& Licensing

Reprints including high resolution figures, can be found at: http://n.neurology.org/content/73/19/1602.full

Information about reproducing this article in parts (figures,tables) or in its entirety can be found online at:

http://www.neurology.org/about/about_the_journal\#permissions

Information about ordering reprints can be found online:

http://n.neurology.org/subscribers/advertise

Neurology ${ }^{\circledR}$ is the official journal of the American Academy of Neurology. Published continuously since 1951, it is now a weekly with 48 issues per year. Copyright . All rights reserved. Print ISSN: 0028-3878. Online ISSN: 1526-632X.

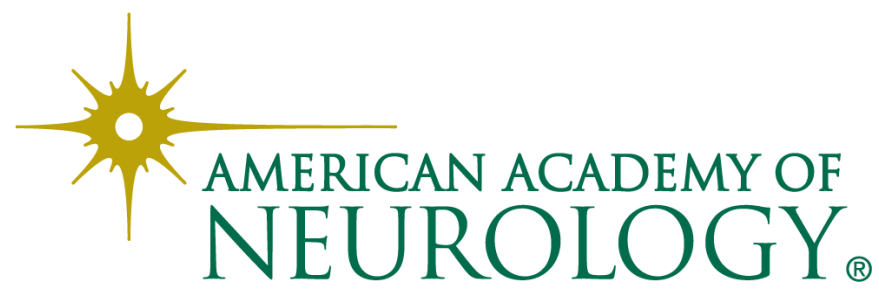

